\title{
Efecto de la Maca Peruana (Lepidium meyenii) y de la Melatonina Sobre el Desarrollo Testicular del Ratón Expuesto a Hipoxia Hipobárica Continua
}

\author{
Effect of Peruvian Maca (Lepidium meyenii) and Melatonin on Testicular \\ Development of Mice Exposed to Continuous Hypobaric Hypoxia
}

\author{
Mario Valenzuela-Estrada*; Roberto Parra*; Juan P. Velasco-Martín*; \\ Hipólito Núñez; Javier Regadera** \& Eduardo Bustos-Obregón***
}

\begin{abstract}
VALENZUELA-ESTRADA, M.; PARRA, R.; VELASCO-MARTÍN, J. P.; NÚÑEZ, H.; REGADERA, J. \& BUSTOS-OBREGÓN, E. Efecto de la maca peruana (Lepidium meyenii) y de la melatonina sobre el desarrollo testicular del ratón expuesto a hipoxia hipobárica continua. Int. J. Morphol., 32(1):70-78, 2014.
\end{abstract}

RESUMEN: El estudio de la hipoxia hipobárica $(\mathrm{HH})$ determina un problema de salud pública y laboral en poblaciones que habitan en zonas de altura. La disminución del oxígeno afecta a diferentes órganos, incluyendo el testículo. El organismo responde frente a la hipoxia estimulando la angiogénesis, el flujo sanguíneo testicular e incrementa la temperatura intraescrotal, lo cual produce un daño de la espermatogénesis. Nuestro estudio valoró el efecto que produce la HH sobre el testículo del ratón. Se utilizó una cámara hipobárica regulada a 4.200 metros sobre el nivel del mar (msnm), en periodos de hipoxia durante 8,3; 16,6 y 24,9 días, en comparación a un grupo control en normoxia (500 msnm). En estos tres grupos, a unos ratones se administró melatonina, a otros maca (Lepidium meyenii) y a otros la combinación de melatonina y maca. Los objetivos fueron evaluar si la ingesta de maca protege al testículo, reduciendo el daño generado por la hipoxia, y determinar un posible efecto sinérgico de la melatonina y de la maca. La exposición a HH continua produjo una disminución del diámetro de los túbulos seminíferos y del lumen tubular; además, el seminograma demostró una reducción del recuento espermático, un aumento de la teratozoospermia y una reducción de la calidad del ADN espermático. La administración de maca aislada o la combinación de maca y melatonina en animales sometidos a HH produjo una notable mejoría de los parámetros relacionados con la función de los espermatozoides, siendo significativos la disminución del número de espermatozoides con morfología anormal y de la compactación del DNA, alcanzando en algunos casos valores próximos a los de los animales normóxicos. Los datos del presente modelo de $\mathrm{HH}$ corroboran los excelentes beneficios que la ingesta de maca tiene sobre la capacidad reproductiva de poblaciones que viven en áreas geográficas de grandes alturas.

PALABRAS CLAVE: Hipoxia; Testículo; Maca; Melatonina; Poblaciones de Altura.

\section{INTRODUCCIÓN}

La maca (Lepidium meyenii) descrita por Gerhard Walpers en 1843, es una planta perenne, cuyas hojas pequeñas y onduladas se desarrollan muy cerca del suelo. Su tubérculo se asemeja a un gran rábano, de color blancoamarillento, que sobrepasa los $8 \mathrm{~cm}$ de diámetro. El tubérculo, debido a su alto valor nutritivo es consumido secado y pulverizado como suplemento de otros alimentos o en infusión (Cikutovic et al., 2009; Gonzales et al., 2013). La maca crece a $4.000 \mathrm{~m}$ de altura y es cultivada en los Andes peruanos, chilenos y bolivianos desde hace 2.000 años
(Gonzales, 2012; Gonzales et al., 2013). La maca contiene proteínas, grasas, glúcidos, calcio, celulosa, almidones, fósforo, yodo, hierro, complejo de vitaminas B y vitamina C (Canales et al., 2000); además, la maca tiene la más alta concentración de proteínas y calcio que cualquier otro tubérculo y también contiene zinc, lo cual favorece la oxigenación de los tejidos. La maca posee 9 de los 10 aminoácidos esenciales, que le confieren propiedades preventivas y curativas y su ingesta no tiene restricciones ni contraindicaciones (Canales et al.).

\footnotetext{
* Departamento de Biología, Facultad de Ciencias, Universidad de Tarapacá, Arica, Chile.

** Departamento de Anatomía, Histología y Neurociencia, Facultad de Medicina, Universidad Autónoma de Madrid, Madrid, España.

*** Laboratorio de Biología de la Reproducción, Facultad de Medicina, Universidad de Chile, Santiago, Chile.
} 
Estudios clínicos han demostrado que la maca es eficaz en la disfunción eréctil (Zenico et al., 2009; Gonzales) e incrementa el recuento de espermatozoides y su motilidad (Gonzales). La maca se utiliza como tratamiento en la astenozospermia y oligozospermia, aumentando el volumen de semen, y el número y la motilidad de espermatozoides. La maca tiene un papel protector del daño testicular producido por insecticidas (Bustos-Obregón et al., 1998) incluido el malatión (Bustos-Obregón et al., 2007). La "maca negra" (Lepidium meyenii), es un tipo de antioxidante natural, dentro del grupo de los flavonoides, aumentando los niveles de espermatozoides a los 7 días y previendo el daño espermatogénico a la hipoxia (Yucra et al., 2008). La "maca roja" reduce el tamaño de la próstata en ratas con hiperplasia benigna.

La HH en los Andes y en otras "regiones de altura", produce alteraciones en la función del ARM y causa degeneración del epitelio seminífero (Liao et al., 2010). Animales expuestos de manera continua o discontinua a ambientes hipóxicos reales o simulados en el laboratorio presentan destrucción del epitelio germinal, alteraciones del transporte de espermatozoides a nivel epididimario y atrofia testicular (Bustos-Obregón et al., 2006). El estrés oxidativo participa en la etiología de las alteraciones de la fertilidad. Los antioxidantes, incluida la melatonina (Vargas et al., 2011), protegen el daño a los espermatozoides por estrés oxidativo, y su administración mejora el daño reproductivo provocado por pesticidas organofosforados. Está establecido que la melatonina tiene un efecto protector en varios modelos de estrés oxidativo celular, debido a la generación de especies reactivas de oxígeno (ROS). La melatonina estimula la actividad de las enzimas que metabolizan los ROS (Vargas et al.).

La hipoxia varía según la altura sobre el nivel del mar, considerándose niveles altos (2438-3658 m) y muy altos (3658-5487 m) (Pugh, 1962). La presión atmosférica a los $1.000 \mathrm{~m}$ es solamente de $674 \mathrm{~mm}$ de $\mathrm{Hg}$, y a los $4.000 \mathrm{~m}$ es de $462 \mathrm{~mm}$ de $\mathrm{Hg}$ y la presión parcial de oxígeno también desciende considerablemente; estos cambios disminuyen la presión parcial en el aire alveolar, la saturación de la hemoglobina sanguínea, y el suministro de oxígeno a los tejidos (Barnholt et al., 2006). La hipoxia aguda en altura reduce las funciones reproductivas en el hombre, pero no está claro que la hipoxia crónica reduzca la fertilidad entre los nativos residentes en zonas de altura (Vitzthum \& Wiley, 2003). Estudios previos han demostrado que la hipoxia disminuye la fertilidad en el hombre (Okumura et al., 2003) y otros mamíferos (Bustos-Obregón et al., 2006), afectando al ciclo celular y a la espermatogénesis. Como respuesta a la hipoxia tisular se produce vasodilatación y angiogénesis, aumentándose así el volumen sanguíneo, pero este aumento de la temperatura intraescrotal determina un daño en la espermatogénesis. Sin embargo, aún no se conoce bien cómo influye la concentración de oxígeno, en los mecanismos moleculares que regulan la espermatogénesis (Vargas et al.). Es posible que en el daño testicular secundario a la hipoxia puedan asociarse alteraciones de la regulación en el eje hipotálamo-hipofisario-testicular (Farias et al., 2008), ya que se ha visto alteraciones de la testosterona en hombres que están sometidos a hipoxia y restricción calórica (Barnholt et al.).

En definitiva, está establecido que los estados de hipoxia determinan un aumento de las especies reactivas de oxígeno (ROS) que deterioraran la membrana de los espermatozoides. La melatonina es un eficaz protector de ADN nuclear, proteínas y lípidos y es un potente antioxidante depurador de radicales libres y altamente específica contra la peroxidación lipídica secundaria a la hipoxia. Todos estos datos sugieren que la administración de melatonina pudiera tener un efecto protector de la estructura y función testicular en ratones (Othman et al., 2001).

El objetivo de este trabajo es, de una parte, valorar el daño testicular de ratones expuestos a HH continua, así como las alteraciones morfológicas y la compactación del DNA de los espermatozoides. De otra parte, se pretende investigar el efecto de la melatonina y maca, administradas bien aisladamente o bien combinadas, como agentes protectores de la estructura y de la función testicular en este modelo de $\mathrm{HH}$ continua.

\section{MATERIAL Y MÉTODO}

Se utilizaron ratones macho (M. musculus) de aproximadamente 3 meses ( 6 ratones por grupo) a los que se sometió a HH durante 8,3, 16,6 y 24,9 días (3 ciclos), (periodos publicados previamente por Farias et al. y por Liao et al.).

Grupos de estudio: Con el fin de estudiar cada estadio de espermatogénesis, se evaluaron un total de 14 grupos: a un grupo se le administró maca, vía oral $(66,6 \mathrm{mg} / \mathrm{Kg}$ de peso corporal) todos los días; a otro grupo se le administró la melatonina $(10 \mathrm{mg} / \mathrm{Kg}$ de peso corporal) diluida en una mezcla de agua-alcohol, y a un tercer grupo se le combinó la maca y la melatonina. Todos estos grupos experimentales fueron comparados con un grupo control en normoxia (500 msnm, la altura de la ciudad de Santiago). Los resultados se compararon con los datos obtenidos en animales sometidos a HH continua (Cámara Hipobárica, Laboratorio de Biología de la Reproducción (Prof. BustosObregón), Facultad de Medicina Universidad de Chile). Después de sacrificar a los animales, se extirpó el testículo izquierdo y se fijó por inmersión en Bouin acuoso (30 mi- 
VALENZUELA-ESTRADA, M.; PARRA, R.; VELASCO-MARTíN, J. P.; NÚÑEZ, H.; REGADERA, J. \& BUSTOS-OBREGóN, E. Efecto de la maca peruana (Lepidium meyenii) y de la melatonina sobre el desarrollo testicular del ratón expuesto a hipoxia hipobárica continua. Int. J. Morphol., 32(1):70-78, 2014.

nutos) más tarde se realizó un corte tanto en el polo craneal como caudal y 2 horas más tarde se realizó un corte completo en el segmento ecuatorial del testículo y se completó la fijación durante las siguientes 12 horas. Se realizó la inclusión en paraplast y se obtuvieron cortes de 5 micras, que fueron teñidos con hematoxilina-eosina (H-E). El análisis morfométrico incluyó: 1) altura del epitelio seminífero, 2) diámetro tubular, 3) superficie del epitelio y 4) superficie del lumen tubular (Fig. 1a). Las mediciones se realizaron en un total de 100 tubos seminíferos por cada ratón (600 tubos por cada subgrupo), mediante el programa "MicrometricTM SE Premium Camará Digital Olympus 2009. Además, en cada corte se determinó el numero de tubos que se encontraban en el estadio VI del ciclo del epitelio seminífero (el cual dura 18,1 horas), ya que en su etapa final las espermatogonias se dividen y forman los espermatocitos preleptoténicos.

De la cauda epididimaria, nada más ser separada del testículo y previa a su fijación, se obtuvo una suspensión espermática. Para ello, se troceó el epidídimo sobre una placa Petri que contenía $5 \mathrm{ml}$ de PBS. El macerado quedó en reposo por 2 horas a $4^{\circ} \mathrm{C}$ y luego se filtró con gasa doble para eliminar los restos de tejido. Se realizó un recuento de espermatozoides en cámara de Neubauer. La muestra se lavó mediante dos centrifugados con PBS a 800 g durante 10 minutos y la fracción celular se ajustó con PBS a una concentración de espermatozoides de 10 millones/ml. Para el análisis de la morfología se colocó una gota de espermatozoides lavados y se dejó secar (sin hacer un frotis). La muestra se fijó en etanol $70^{\circ}$ durante 1 minuto, antes de su tinción con hematoxilina de Harris durante 10 segundos. Se realizó un lavado de 10 minutos con agua corriente, previo a otro de 1 minuto con agua destilada y se tiñó en Eosina acuosa al $1 \%$ durante 5 minutos, lavándose con agua destilada. El análisis de los espermatozoides se realizó con un microscopio óptico con aumento de 1000x.

Se evaluó el patrón de desnaturalización del ADN de los espermatozoides, mediante el test de fluorescencia de anaranjado de acridina (Tejada et al., 1984). Para ello, una suspensión de espermatozoides lavados se indujo la desnaturalización del $\mathrm{ADN}$ nativo mediante un choque térmico de $90^{\circ} \mathrm{C}$ durante 6 minutos. A continuación, los espermatozoides se fijaron en solución Carnoy (metanolácido acético, $3: 1$ ), durante 2 horas, en frío y oscuridad, seguido de lavado con PBS a 1100 g (5 minutos) y se tomó una gota del "pellet" que se depositó en un portaobjeto, dejando secar al aire durante 20 minutos. Los frotis fueron almacenados en frío y oscuridad hasta el momento de la tinción con anaranjado de acridina (AO). Los frotis fueron teñidos, en frío $\left(4^{\circ} \mathrm{C}\right)$ y en oscuridad, con 2-3 gotas del fluorocromo AO, a una concentración final de $0,19 \mathrm{mg} / \mathrm{ml}$ y
pH 2.5, durante 3-5 minutos, después se lavaron 3 veces con agua desionizada, para retirar el exceso de fluorocromo, y se montaron con agua destilada y almacenaron en oscuridad y frío hasta su lectura. El grado de compactación del DNA se valoró con un citofotómetro Zeiss M 0.1 de epifluorescencia, calibrado a un $100 \%$ de emisión de fluorescencia a $524 \mathrm{~nm}$. Se evaluaron las cabezas de espermatozoides (normales y anormales), en los grupos experimentales y en el de control, teniendo presente que el fluorocromo naranja de acridina emite fluorescencia roja al unirse al ADN de hebra única y fluorescencia verde al unirse a ADN en estado de doble hebra (Tejada et al.).

El estudio estadístico se realizó con el programa SPSS en su versión 10.0 y se compararon los valores promedios y las desviaciones estándar de los grupos de animales sometidos a normoxía versus hipoxia sin tratamiento y en los tres grupos de ingesta de antioxidantes. Posteriormente, se hizo una comparación múltiple de medias mediante el análisis de varianza (ANOVA), con una significancia $p<0,05$.

\section{RESULTADOS}

El estudio morfométrico de los cambios testiculares secundarios a la $\mathrm{HH}$, realizados a los 4 meses post-maduración, así las modificaciones de los parámetros evaluados, en relación con los tratamientos de melatonina o de maca y de la administración conjunta de melatonina y maca, en los tres diferentes tiempos de hipoxia se han incluido en la Tabla I. Los animales con HH presentaron notables alteraciones del testículo, en comparación con los animales en normoxia (Figs. 1a y b). El peso del testículo fue significativamente menor en los animales hipoxicos, contrariamente al peso de la cauda del epidídimo que fue significativamente mayor (Tabla I). El estudio morfométrico de los tubos seminíferos demostró que los animales hipóxicos tenían una disminución significativa del diámetro tubular e importantes alteraciones de la espermatogénesis (Fig. 1b). Así, en los animales hipoxicos sin tratamiento, el número de tubos seminíferos con espermatogénesis completa (estadio tubular VI) fue cinco veces menor que en el grupo control de animales normóxicos (Tabla I). El estudio de los espermatozoides obtenidos de la cola del epidídimo demostró que los animales hipóxicos sin tratar tenían un significativo menor recuento de espermatozoides, siendo extraordinariamente alto el número de espermatozoides con morfología anormal. Por último, las alteraciones en la compactación del ADN de los espermatozoides fueron significativamente superiores a las observadas en los animales normóxicos (grupo control) (Tabla I). 


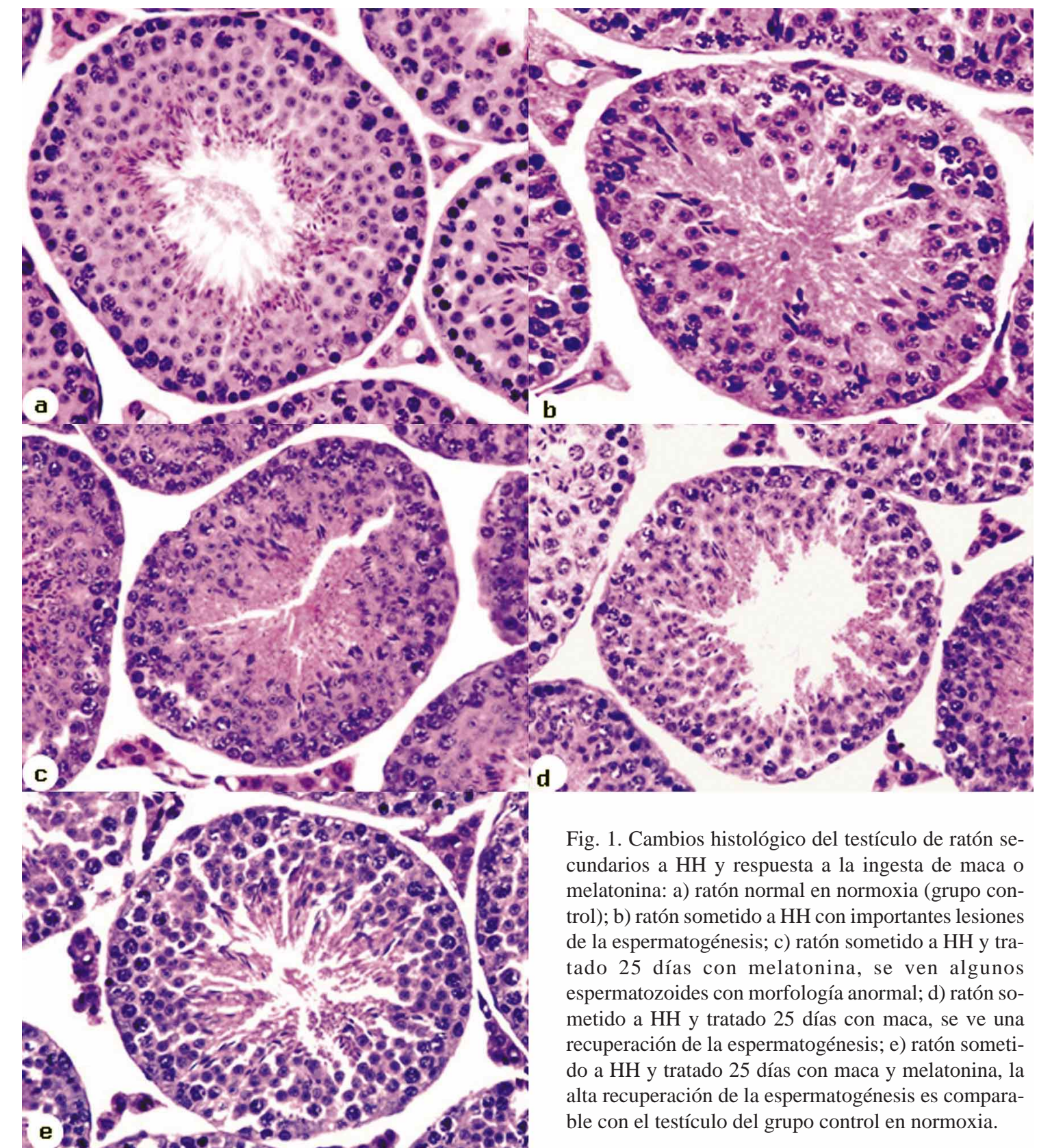

En relación con el tratamiento de melatonina y maca, administrados independiente o conjuntamente (maca y melatonina) en los grupos de $\mathrm{HH}$, los estudios morfométricos testiculares y de los espermazoides (Tabla I) demostraron que a los ocho días del tratamiento los datos referidos al peso del testículo y el tamaño de los tubos seminíferos han sido bastante heterogéneos; pero la ingesta de maca y melatonina durante 16 y 24 días produjo, en general, una mejoría, acercándose a los valores de normoxia, tanto del diámetro tubular, como de la altura del epitelio tubular, así como una significativo aumento del recuento espermático, y una disminución del numero de espermatozoides con alteraciones morfológicas (Figs. 1c-e); además las tres pautas de tratamientos con maca y/o melatonina consiguieron una normalización del daño de DNA causada por la HH; de hecho, el estudio estadístico demostró diferencias significativas del diámetro tubular y de la altura del epitelio tubular, entre el grupo tratado con melatonina y el grupo del tratamiento combinado de melatonina y maca (Tabla I y Figs. 1 c-e). También se encontraron diferencias significativas entre el grupo tratado con melatonina y el tratado solo con maca, cuando se evaluó el estadio tubular VI y la morfología espermática anormal (Tabla I). 
VALENZUela-ESTRADA, M.; PARRA, R.; VELASCO-MARTíN, J. P.; NÚÑEZ, H.; REGADERA, J. \& BUSTOS-OBREGóN, E. Efecto de la maca peruana (Lepidium meyenii) y de la melatonina sobre el desarrollo testicular del ratón expuesto a hipoxia hipobárica continua. Int. J. Morphol., 32(I):70-78, 2014.

Tabla I. Efecto de la HH continua, de maca y melatonina sobre los parámetros reproductivos del ratón.

\begin{tabular}{|c|c|c|c|c|c|}
\hline Tiempo / Tratamiento & Normoxia & Hipoxia S/Trat. & Hipoxia 8,3 d & Hipoxia 16,6 d & Hipoxia 24,9 d, \\
\hline Peso Testículo & $248,8 \pm 1,7$ & $177,0 \pm 2,4^{\mathrm{a}}$ & & & \\
\hline Melatonina & & & $130,4 \pm 6,1^{\mathrm{b}}$ & $91,0 \pm 15,2 \mathrm{~b}$ & $189,6 \pm 46,5$ \\
\hline Melat/Maca & & & $124,9 \pm 7,3^{\mathrm{b}}$ & $120,1 \pm 21,0 \mathrm{~b}$ & $174,1 \pm 25,2$ \\
\hline Maca & & & $130,8 \pm 7,7^{\mathrm{b}}$ & $134,6 \pm 18,7 \mathrm{~b}$ & $143,5 \pm 21,3 \mathrm{c}$ \\
\hline Peso Cauda Epid. & $26,4 \pm 1,3$ & $41,0 \pm 7,0 \mathrm{a}$ & & & \\
\hline Melatonina & & & $24,1 \pm 5,8^{b}$ & $37,5 \pm 7,5$ & $41,7 \pm 7,8$ \\
\hline Melat/Maca & & & $28,0 \pm 2,0^{\mathrm{b}}$ & $37,2 \pm 6,5$ & $34,7 \pm 9,1$ \\
\hline Maca & & & $24,9 \pm 8,1^{\mathrm{b}}$ & $37,6 \pm 9,4$ & $29,2 \pm 10,0$ \\
\hline Diámetro Tubular & $217,9 \pm 18,9$ & $171,7 \pm 11,9^{\mathrm{a}}$ & & & \\
\hline Melatonina & & & $216,6 \pm 21,7^{\mathrm{b}}$ & $189,3 \pm 10,7$ & $188,6 \pm 12,9$ \\
\hline Melat/Maca & & & $200,7 \pm 27,0^{\mathrm{b}}$ & $199,1 \pm 15,0$ & $207,2 \pm 11,2 b$ \\
\hline Maca & & & $209,8 \pm 12,1^{\mathrm{b}}$ & $193,3 \pm 15,5 b$ & $187,1 \pm 17,4$ \\
\hline S. Epitelio Seminífero & $28387,1 \pm 2731,8$ & $26605 \pm 2953,0$ & & & \\
\hline Melatonina & & & $27239,6 \pm 3247,6$ & $23760,9 \pm 3314,8$ & $21837,8 \pm 3380,3$ \\
\hline Melat/Maca & & & $26110,8 \pm 3977,1$ & $25020,8 \pm 3181,5$ & $24176,8 \pm 2179,85$ \\
\hline Maca & & & $26270,9 \pm 1966,0$ & $24662,7 \pm 1881,4$ & $20171,3 \pm 3565,8^{b}$ \\
\hline S. Lúmen Tubular & $3232,8 \pm 878,7$ & $2595,8 \pm 348,7$ & & & \\
\hline Melatonina & & & $2687,5 \pm 229,4$ & $2194,2 \pm 740,7$ & $2904,2 \pm 556,9$ \\
\hline Melat/Maca & & & $2549,3 \pm 560,4$ & $3063,8 \pm 250,6$ & $2725,4 \pm 587,5$ \\
\hline Maca & & & $2575,1 \pm 306,9$ & $2185,2 \pm 562,6$ & $2142,6 \pm 645,1$ \\
\hline Altura Epitelio Tubular & $60,3 \pm 7,4$ & $52,3 \pm 6,0$ & & & \\
\hline Melatonina & & & $44,0 \pm 4,3$ & $42,3 \pm 4,3$ & $49,2 \pm 4,7$ \\
\hline Melat/Maca & & & $47,9 \pm 6,2$ & $43,4 \pm 3,2$ & $57,5 \pm 4,5$ \\
\hline Maca & & & $54,9 \pm 4,2$ & $49,3 \pm 6,4$ & $54,4 \pm 3,4$ \\
\hline Estadio Tubular VI & $25,6 \pm 1,8$ & $4,8 \pm 1,0 \mathrm{a}$ & & & \\
\hline Melatonina & & & $4,3 \pm 0,8$ & $5,1 \pm 2,1$ & $3,4 \pm 1,3$ \\
\hline Melat/Maca & & & $8,4 \pm 3,3 b$ & $8,4 \pm 3,4$ & $6,0 \pm 2,6$ \\
\hline Maca & & & $14,8 \pm 2,3^{\mathrm{b}}$ & $8,6 \pm 4,5^{\mathrm{b}, \mathrm{cd}}$ & $8,1 \pm 1,8^{\mathrm{c}}$ \\
\hline Recuento Esperm Epid. & $2,1 \pm 0,4$ & $0,2 \pm 0,1 \mathrm{a}$ & & & \\
\hline Melatonina & & & $1,3 \pm 0,5$ & $0,7 \pm 0,4$ & $1,1 \pm 0,3$ \\
\hline Melat/Maca & & & $1,9 \pm 0,8 \mathrm{~b}$ & $0,7 \pm 0,3$ & $0,9 \pm 0,1$ \\
\hline Maca & & & $2,1 \pm 1,1 \mathrm{~b}$ & $0,9 \pm 0,4$ & $1,2 \pm 0,6$ \\
\hline Morfologia Esperm. Anorm. & $2,8 \pm 0,5$ & $46,4 \pm 5,7 \mathrm{a}$ & & & \\
\hline Melatonina & & & $17,2 \pm 4,6^{\mathrm{b}}$ & $14,2 \pm 5,3^{\mathrm{b}}$ & $12,5 \pm 4,8^{\mathrm{b}}$ \\
\hline Melat/Maca & & & $16,3 \pm 4,4^{\mathrm{b}}$ & $5,2 \pm 2,4^{\mathrm{b}}$ & $7,3 \pm 3,6^{\mathrm{b}}$ \\
\hline Maca & & & $26,7 \pm 9,5^{b^{d}}$ & $4,5 \pm 3,0^{\mathrm{b}}$ & $6,8 \pm 2,2^{\mathrm{b}}$ \\
\hline Compactación ADN Esperm. & $8,6 \pm 5,5$ & $22,3 \pm 1,7 \mathrm{a}$ & & & \\
\hline Melatonina & & & $6,0 \pm 2,3 \mathrm{~b}$ & $6,1 \pm 5,4^{\mathrm{b}}$ & $6,4 \pm 3,7^{\mathrm{b}}$ \\
\hline Melat/Maca & & & $10,3 \pm 3,8^{\mathrm{b}}$ & $5,8 \pm 2,2^{\mathrm{b}}$ & $6,5 \pm 2,9^{\mathrm{b}}$ \\
\hline Maca & & & $4,9 \pm 2,3 \mathrm{~b}$ & $3,2 \pm 2,8^{\mathrm{b}}$ & $4,5 \pm 2,6^{\mathrm{b}}$ \\
\hline
\end{tabular}

Epid: Epidídimo. S: Superficie. Esperm: Espermático. a: $\mathrm{p}<0.05$ respecto de Normoxia; b: $\mathrm{p}<0.05$ respecto de Hipoxia sin Tratamiento; c: $\mathrm{p}<0.05$ respecto de Hipoxia tratada con Melatonina; d: $\mathrm{p}<0.05$ respecto Hipoxia tratada con Melatonina/Maca.

\section{DISCUSIÓN}

Está establecido que la $\mathrm{HH}$ es responsable de alteraciones en la estructura y función del ARM y que la administración de maca activa la espermatogénesis, previniendo la interrupción de la espermatogénesis secundaria a HH (Bustos-Obregón et al., 2007). Sin embargo, hasta el presente estudio no se han evaluado los cambios morfométricos de los tubos seminíferos, cuando se administra maca y melatonina, bien aisladamente o bien combinadas, ni tampoco se ha investigado si estas sustancias causan alteraciones morfologías o funcionales de los espermatozoides y de la desnaturalización del DNA. 
En relación al peso testicular, se ha encontrado un disminución significativa en los animales hipóxicos con respecto a los normóxicos, datos que corroboran estudios previos (Farias et al.); al contrario, el peso epididimario fue significativamente mayor en el grupo de $\mathrm{HH}$; mientras que el recuento de espermatozoides en la cola del epidídimo fue significativamente menor (Tabla I), lo que coincide con lo publicado previamente, indicando un evidente daño en la espermatogénesis (Bustos-Obregón et al., 1998).

Está bien establecidas las acciones antioxidantes de la melatonina y de la maca, determinando un papel protector testicular al reducir el daño generado por la hipoxia crónica. La administración de extracto de maca a roedores aumenta el tamaño del testículo y del epidídimo (Gonzáles et al., 2004). En nuestro estudio se comprobó una disminución significativa del diámetro tubular y del recuento de espermatozoides en el epidídimo en los animales con $\mathrm{HH}$, lo que confirma estudios previos (Bustos-Obregón et al., 2006; Farias et al.; Cikutovic et al.). Se ha sugerido que la $\mathrm{HH}$ alteraría la proliferación (mitosis) de las espermatogonias y cambios morfológicos de los espermatozoides (BustosObregón et al., 2006; Farias et al.), lo cual estaría en parte relacionado con la disminución de la FSH, LH y testosterona presente en la $\mathrm{HH}$ (Farias et al.); pero estos datos son contradictorios, ya que recientemente se ha publicado que ratas sometidas a hipoxia crónica tienen bajos niveles de testosterona y altos de LH y FSH, indicando una lesión primaria testicular (Zhang et al., 2013).

Se sabe que la melatonina y la maca tienen acciones antioxidantes sobre el testículo y que, en concreto, la maca es eficaz en la disfunción sexual e incrementa el recuento de espermatozoides y su motilidad (Gonzales) y reduce el daño generado por la hipoxia. En el presente trabajo de $\mathrm{HH}$ en ratas hemos demostrado que, si bien la administración aislada o en combinación de maca y melatonina no modifica el peso testicular, ambas sustancias administradas durante la hipoxia sí consiguen un incremento significativo del diámetro de los tubos seminíferos, acercándose a los valores del normoxia, sobre todo cuando se administran combinadamente maca y melatonina (Tabla I). Por el contrario, no hemos evidenciado cambios de la superficie del epitelio seminífero, de la superficie del lumen tubular ni de la altura del epitelio tubular en los animales hipóxicos con respecto a los normóxicos, y tampoco se han visto cambios de estos parámetros en relación con la administración de maca y melatonina; estos datos difieren de un estudio previo (Vargas et al.) en el que se demostró una disminución de la altura del lumen tubular en los anímales sometidos a hipoxia crónica. Es posible que estos datos contradictorios puedan ser debidos a diferencias de la tolerancia de cada animal frente a la hipoxia (Ghosh et al., 2012). Hemos demostrado que el número de tubos seminíferos en estadio VI (un segmento relativamente largo de la espermatogénesis de roedores) es cinco veces menor en los animales hipóxicos que en los normóxicos $(\mathrm{p}<0,05)$; sin embargo, ninguno de los tratamientos con maca y melatonina consiguió mejorar este parámetro. Con respecto a los estadios del ciclo seminífero, se ha publicado que la altitud reduce la frecuencia de tubos en estadio VIII (espermiación), y que la administración de maca previene la interrupción de la espermatogénesis inducida por hipoxia (Rojas et al., 2005); además, la ingesta de maca incrementa el recuento espermático y la longitud del estado VIII y la frecuencia de los estadios IX-XII de la espermatogénesis (mitosis de espermatogonias) (Gonzales et al., 2004). También estudios de toxicología reproductiva experimental han referido aumento de la longitud de los estadios VII y VIII en respuesta a la administración del tóxico organofosforado malathion y que la ingesta de maca protegía este daño tubular (Bustos-Obregón et al., 2007).

La cuantificación de las anomalías morfológicas de los espermatozoides constituye en el hombre uno de los criterios estrictos de la OMS en la evaluación del seminograma y también es un dato de gran valor en la evaluación de la biopsias de pacientes que consultan por infertilidad (Franken \& Oehninger, 2012). Los animales con $\mathrm{HH}$ tuvieron altísimos valores de espermatozoides con anomalías morfológicas que afectaban al núcleo, la pieza intermedia y/o al flagelo. Las tres pautas terapéuticas (ingesta de maca y melatonina aisladas o la administración combinada) obtuvieron un efecto beneficioso, de modo que el número de espermatozoides con anomalías morfológicas fue significativamente menor $(p<0,05)$ en todos los diferentes tipos de tratamiento, con respecto al grupo de $\mathrm{HH}$ sin tratamiento, pero sin alcanzar los valores basales del grupo control de normoxia. Es de destacar que los mejores resultados se obtuvieron en el grupo que ingirieron maca, seguido de los que recibieron la combinación de maca y melatonina. Esto datos confirman el efecto beneficioso del consumo de maca sobre la espermatogénesis en la HH. Este efecto beneficioso de la maca ha sido corroborado recientemente en hombres que viven a $4.000 \mathrm{~m}$ de altura, ya que la ingesta de maca ha obtenido un mejor índice general de salud $(p<0,01)$, disminuyendo la interleukina Il-6 (biomarcador inflamatorio), con respecto al grupo privado de este tubérculo $(\mathrm{p}<0,05)$ (Gonzales et al., 2013).

El grado de compactación del ADN es uno de los parámetros que mejor valora el estado funcional y la calidad fertilizante de los espermatozoides, y en los hombres infértiles frecuentemente se observa fragmentación del DNA 
VALENZUELA-ESTRADA, M.; PARRA, R.; VELASCO-MARTíN, J. P.; NÚÑEZ, H.; REGADERA, J. \& BUSTOS-OBREGóN, E. Efecto de la maca peruana (Lepidium meyenii) y de la melatonina sobre el desarrollo testicular del ratón expuesto a hipoxia hipobárica continua. Int. J. Morphol., 32(1):70-78, 2014.

(Gallegos et al., 2008). En el presente estudio se observó un aumento significativo del porcentaje de inestabilidad del ADN espermático en el grupo de $\mathrm{HH}$. Se ha sugerido que la baja concentración de oxígeno en hipoxia de altura extrema, asociado a los cambios homeostáticos de la temperatura testicular, pudieran ser mecanismos implicados en la disminución de la producción de espermatozoides (Cikutovich et al.). En los tres periodos de $\mathrm{HH}$ evaluados, la administración de melatonina y/o maca obtuvieron una importante mejoría de la compactación del ADN espermático (Tabla I), dado que el porcentaje de espermatozoides con ADN inestable alcanzó cifras menores, incluso que las obtenidas en los ratones normóxicos, siendo el tratamiento con maca el que obtuvo los mejores resultados antioxidantes. Se sabe que las especie reactivas de oxigeno (ROS) aumentan durante la hipoxia y que la melatonina tiene un efecto antioxidante. Las ROS provocan daño estructural del ADN y muerte celular, al aumentar la permeabilidad de la membrana plasmática e inactivar los sistemas enzimáticos celulares (Vargas et al.). Durante la hipoxia, los radicales libres generan pérdidas en el control celular (incluido mutaciones), y la administración de maca reduce estos efectos nocivos. En relación con la fertilidad masculina, el incremento de ROS induce aumento de apoptosis de las células germinales (Zepeda et al., 2014), lo que explicaría las lesiones de hipoespermatogénesis encontradas en nuestro modelo experimental de $\mathrm{HH}$.

Histológicamente, hemos encontrado lesiones de hipoespermatogénesis secundaria a la $\mathrm{HH}$, pero en grado variable, dependiendo de la adaptación particular de cada animal a la $\mathrm{HH}$, confirmándose que la hipoxia ejerce un efecto deletéreo sobre la espermatogénesis, afectando la maduración de las espermátides y de los espermatozoides (espermiación), pero también en algunos casos provocando una disminución de los espermatocitos primarios (células tetraploides), los cuales pudieran sufrir apoptosis. Referente a la apoptosis, se ha publicado que también está incrementada en las espermatogonias basales de los animales sometidos a hipoxia (Liao et al.). En general, estas alteraciones del daño morfológico y funcional de las espermátides y de los espermatozoides sometidos a $\mathrm{HH}$ regresionaron cuando se les administró solamente maca, o en combinación con melatonina, durante los 25 días que duró el presente modelo experimental de $\mathrm{HH}$. Nuestros datos experimentales están en consonancia con los observados en trabajadores a grandes altitudes, que desarrollaron mecanismos de estrés oxidativo en las células espermatogénicas, repercutiendo en la fertilidad de algunos de estos pacientes (Zepeda et al.). También hombres sometidos a restricción calórica (anoréxicos) y a hipoxia de gran altura presentaron una más lenta respuesta hormonal de adecuación a la hipoxia (Barnholt et al.). Estos datos son congruentes con nuestro modelo experimental de $\mathrm{HH}$, ya que la ingesta continua de maca, si bien no produce cambios notorios del tamaño tubular, sí mejoraron significativamente los parámetros morfométricos (morfología espermática y compactación del DNA) relacionados con una mejor capacidad fecundante de los espermatozoides.

En definitiva, la exposición a HH continua alteró el ARM del ratón, observándose una disminución significativa del peso del testículo y del diámetro de los túbulos seminíferos y del recuento de espermatozoides en el epidídimo; asimismo, la hipoxia determinó un importante aumento del número de anomalías morfológicas de los espermatozoides (teratozoospermia) y una reducción significativa de la compactación del DNA del espermatozoide, datos relacionados con el estrés oxidativo y la disminución de la capacidad fertilizante. En el presente modelo de $\mathrm{HH}$ crónica (que reproduce las condiciones de hipoxia a grandes alturas), la ingesta de melatonina y maca (sustancias antioxidantes) produjo una recuperación parcial del diámetro tubular y de la altura del epitelio tubular, acercándose a los valores de Normoxia. La administración de maca, tanto aisladamente como combinada con melatonina, claramente mejoraron los parámetros relacionados con la función de los espermatozoides (disminución del numero de espermatozoides con morfología anormal y de la compactación del DNA). Estos datos del presente modelo de $\mathrm{HH}$ corroboran los excelentes beneficios que la ingesta de maca tiene sobre la capacidad reproductiva de poblaciones que viven en áreas geográficas de grandes alturas.

\section{AGRADECIMIENTOS}

Este trabajo fue financiado por la Universidad de Tarapacá (Arica, Chile) Proyecto Mayor de Investigación Científica y Tecnológica UTA, código 4711-13.

VALENZUELA-ESTRADA, M.; PARRA, R.; VELASCOMARTÍN, J. P.; NÚÑEZ, H.; REGADERA, J. \& BUSTOSOBREGÓN, E. Effect of Peruvian maca (Lepidium meyenii) and melatonin on testicular development of mice exposed to continuous hypobaric hypoxia. Int. J. Morphol., 32(1):70-78, 2014.

SUMMARY: Hypobaric hypoxia $(\mathrm{HH})$ is a decisive factor in human health in populations that reside at high altitude levels. Low oxygen rate affects most tissues and organs, including the testis. In humans, hypoxia stimulates angiogenesis, testicular blood flow and increases intrascrotal temperature which determines negative effects on sperm production. Our study researched the effects of HH in mice testicle. Mice were housed in a hypobaric chamber with a setting at $4,200 \mathrm{~m}$ above sea level during three 
different periods of hypoxia $(8.3,16.6$ and 24.9 days). Control groups were housed at normoxic conditions (500 $\mathrm{m}$ above sea level). Hypoxic mice were treated with melatonin, maca plant (Lepidium meyenii) and melatonin and maca combination. The aim of present study was to determine if maca consumption protects testis against harmful effects of hypoxia and to determine a possible synergistic effect between melatonin and maca administration. In this article we have demonstrated that hypoxia produces a considerable decrease of seminiferous tubules diameter and lumen diameter. Moreover, seminogram showed a reduced sperm count, increased teratozoospermia and a reduction of DNA quality. The HH mice treatment with maca or maca-melatonin combination showed statistically significant improvement at sperm function parameters, and in the reduction of sperm morphology abnormalities and DNA compaction, in some cases attaining rates closer to those registered in normoxic mice. Our experimental data corroborates that maca consumption improves reproductive capacity of populations that inhabit high altitude regions.

KEY WORDS: Hypoxia; Testis; Maca; Melatonin; High altitude populations.

\section{REFERENCIAS BIBLIOGRÁFICAS}

Barnholt, K. E.; Hoffman, A. R.; Rock, P. B.; Muza, S. R.; Fulco, C. S.; Braun, B.; Holloway, L,; Mazzeo, R. S.; Cymerman, A. $\&$ Friedlander, A. L. Endocrine responses to acute and chronic high-altitude exposure (4,300 meters): modulating effects of caloric restriction. Am. J. Physiol. Endocrinol. Metab., 290(6):E1078-88, 2006.

Bustos-Obregón, E.; Costa del Río, F. \& Sarabía, L. Morphometric Analysis of Mice Testicular Tubules after Administration of Malathion and Maca. Int J. Morphol., 25(2):245-8, 2007.

Bustos-Obregón, E.; Esveile, C.; Contreras. J.; Maurer, I. \& Sarabia. L. Effects of Chronic Simulated Hypobaric Hypoxia on Mouse Spermatogenesis. Int. J. Morphol., 24(3):481-8, 2006.

Bustos-Obregón, E.; Valenzuela-Estrada, M. \& Rojas, M. Agropesticides and Testicular Damage. In: Francisco MartínezGarcía and Javier Regadera eds.: Male Reproduction: A Multidisciplinary Overview. Madrid, Churchill Comunications Europe España, 1998. pp.257-64.

Canales, M.; Aguilar, J.; Prada, A.; Marcelo, A.; Huamán, C. \& Carvajal, L. Evaluación nutricional de lipidium meyenii (MACA) en ratones albinos y su descendencia. Arch. Latinoam. Nutr., 50(2):126-33, 2000.

Cikutovic, M.; Fuentes, N. \& Bustos-Obregón, E. Effect of intermittent hypoxia on the reproduction of rats exposed to high altitude in the Chilean Altiplano. High Alt. Med. Biol., 10(4):357-63, 2009.

Farias, J. G.; Bustos-Obregón, E.; Tapia, P. J.; Gutierrez, E.; Zepeda,
A.; Juantok, C.; Cruz, G.; Soto, G.; Benites, J. \& Reyes, J. G. Time course of endocrine changes in the hypophysis-gonad axis induced by hypobaric hypoxia in male rats. J. Reprod. Dev., 54(1):18-21, 2008.

Franken, D. R. \& Oehninger, S. Semen analysis and sperm function testing. Asian J. Androl., 14(1):6-13, 2012.

Gallegos, G.; Ramos, B.; Santiso, R.; Goyanes, V.; Gosálvez, J. \& Fernández, J. L. Sperm DNA fragmentation in infertile men with genitourinary infection by Chlamydia trachomatis and Mycoplasma. Fertil. Steril., 90(2):328-34, 2008.

Ghosh, D.; Kumar, R. \& Pal, K. Individual variation in response to simulated hypoxic stress of rats. Indian J. Exp. Biol., 50(10):744-8, 2012.

Gonzáles, G. F. Ethnobiology and Ethnopharmacology of Lepidium meyenii (Maca), a Plant from the Peruvian Highlands. Evid. Based Complement. Alternat. Med., 2012:193496, 2012.

Gonzáles, G. F.; Gasco, M.; Córdova, A.; Chung, A.; Rubio, J. \& Villegas, L. Effect of Lepidium meyenii (maca) on spermatogenesis in male rats acutely exposed to high altitude (4340 m). J. Endocrinol., 180(1):87-95, 2004.

Gonzáles, G. F.; Gasco, M. \& Lozada-Requena, I. Role of Maca (Lepidium meyenii) Consumption on Serum Interleukin-6 Levels and Health Status in Populations Living in the Peruvian Central Andes over $4000 \mathrm{~m}$ of Altitude. Plant Foods Hum. Nutr., 68(4):347-51, 2013.

Liao, W.; Cai, M.; Chen, J.; Huang, J.; Liu, F.; Jiang, C. \& Gao, Y. Hypobaric hypoxia causes deleterious effects on spermatogenesis in rats. Reproduction, 139(6):1031-8, 2010.

Okumura, A.; Fuse, H.; Kawauchi, Y.; Mizuno, I. \& Akashi, T. Changes in male reproductive function after high altitude mountaineering. High Alt. Med. Biol., 4(3):349-53, 2003.

Othman, A. I.; El-Missiry, M. A. \& Amer, M. A The protective action of melatonin on indomethacin-induced gastric and testicular oxidative stress in rats. Redox Reprod., 6(3):173-7, 2001.

Pugh, L. G. Physiological and medical aspects of the Himalayan scientific and mountaineering expedition, 1960-61. Br. Med. J., 2(5305):621-7, 1962.

Rojas, M.; Ronceros, G.; Garcia-Hjarles, M.; Peña, M.; Vivanco, W.; Castillo, O.; Neira, E. \& Castro, A. Eficacia de Lepidium perrianun (maca) en el tratamiento de la astenozooespermia y oligozooespermia, causas de infertilidad masculina. IV Jornadas Científicas Sanfernandinas y VII Jornadas Científicas de Investigación en Salud. An. Fac. Med., 66(Supl. 1), 2005.

Tejada, R. I.; Mitchell, J. C.; Norman, A.; Marik, J. J. \& Friedman, $\mathrm{S}$. A test the practical evaluation of male fertility by acridine orange (AO) fluorescence. Fertil. Steril., 42(1):87-91, 1984. 
VAlEnZUEla-ESTRADA, M.; PARRA, R.; VELASCO-MARTín, J. P.; NÚÑEZ, H.; REGADERA, J. \& BUSTOS-OBREGóN, E. Efecto de la maca peruana (Lepidium meyenii) y de la melatonina sobre el desarrollo testicular del ratón expuesto a hipoxia hipobárica continua. Int. J. Morphol., 32(1):70-78, 2014.

Vargas, A.; Bustos-Obregón, E. \& Hartley, R. Effects of hypoxia on epididymal sperm parameters and protective role of ibuprofen and melatonin. Biol. Res., 44(2):161-7, 2011.

Vitzthum, V. J. \& Wiley, A. S. The proximate determinants of fertility in populations exposed to chronic hypoxia. High Alt. Med. Biol., 4(2):125-39, 2003.

Yucra, S.; Gasco, M.; Rubio, J.; Nieto, J. \& Gonzáles, G. F. Effect of different fractions from hydroalcoholic extract of Black Maca (Lepidium meyenii) on testicular function in adult male rats. Fertil. Steril., 89(5 Suppl.):1461-7, 2008.

Zenico, T.; Cicero, A. F.; Valmorri, L.; Mercuriali, M. \& Bercovich, E. Subjective effects of Lepidium meyenii (Maca) extract on well-being and sexual performances in patients with mild erectile dysfunction: a randomized, double-blind clinical trial. Andrologia, 41(2):95-9, 2009.

Zepeda, A. B.; Figueroa, C. A.; Calaf, G. M. \& Farías, J. G. Male reproductive system and antioxidants in oxidative stress induced by hypobaric hypoxia. Andrologia, 46(1):1-8, 2014.

Zhang, G. L.; Dai, D. Z.; Zhang, C. \& Dai, Y. Apocynin and raisanberine alleviate intermittent hypoxia induced abnormal StAR and 3b-HSD and low testosterone by suppressing endoplasmic reticulum stress and activated p66Shc in rat testes. Reprod. Toxicol., 36:60-70, 2013.
Dirección para Correspondencia:

Prof. Mario Valenzuela-Estrada

Departamento de Biología

Universidad de Tarapacá

Casilla 7-D

Velásquez 1775

Arica

CHILE

Teléfono: : 5658205376

Fax : :5658205484

E-mail: mvalenz@uta.cl

Recibido : 02-10-2013

Aceptado: 17-12-2013 